\author{
Andrzej Zieliński, Lukasz Zborowski \\ Gdansk University of Technology, Faculty of Mechanical Enginering, Narutowicza 11/12, \\ 80-233 Gdansk, Poland
}

\title{
ENVIRONMENTAL DEGRADATION OF TITANIUM ALLOY IN ARTIFICIAL SALIVA
}

\begin{abstract}
The titanium and its alloys are potentially prone to hydrogen embrittlement, including those proposed for dental implants. The research has been aimed to assess a susceptibility to environment-enhanced degradation of the Ti$13 \mathrm{Zr}-13 \mathrm{Nb}$ alloy in artificial saliva with or without hydrofluoric acid, subject or not to cathodic polarisation. The results have shown that even if artificial saliva is safe environment, both cathodic polarization and cathodic current result in brittle cracking. Either hydride-related embrittlement or fluoride-related stress corrosion cracking are considered as potential sources.
\end{abstract}

Key words: titanium alloys, implants, hydrogen degradation, stress corrosion cracking

\section{INTRODUCTION}

The $\mathrm{Ti}$ and its alloys have a number of advantages: high yield stress, low density, high corrosion resistance and biocompatibility and therefore they are increasingly used to fabricate orthopaedic, spinach and dental implants $[1,2]$. The Ni-Ti alloys are used in chirurgy because of shape memory effect [3]. There are only few $\mathrm{Ti}$ alloys approved for their application as implants. Among them, the Ti-13Zr-13Nb of high mechanical properties and low Young modulus, and of an absence of potentially dangerous $\mathrm{Al}$ and $\mathrm{V}$, seems the most suitable candidate alloy to substitute Ti-Al-V material [4]. The presence of $\mathrm{Zr}$ enhances corrosion resistance and $\mathrm{Nb}$ is a stabilizer of $\beta$ phase. The problem of an use of Ti alloys as dental implants and orthodontic wires may be their susceptibility to hydrogen-enhanced cracking and local corrosion in acidic and fluoride containing environments.

Hydrogen appears in in het and bcc titanium as interstitial solutions $\alpha$ i $\beta$, with limit solubility 0.004 mass pct. At high hydrogen fugacity the hydrogen enetering the metal can form hydrides, depending on hydrogen content: $\delta, \varepsilon$ and $\gamma$ hydrides. The $\delta$ fcc $\mathrm{TiH}_{2}$ hydride forms at room temperature at low hydrogen content and may transform into $\varepsilon$ tcp hydride at higher hydrogen content and finally into $\gamma$ hydride at the highest hydrogen amount [5].

The possibility of hydrogen degradation was analysed in a number of early work. In [6] hydrogen embrittlement of a beta titanium orthodontic wire was examined by means of a delayed-fracture test in acidic (acidulated phosphate fluoride APF) and neutral fluoride aqueous solutions. The time to fracture increased with decreasing applied stress in $2.0 \%$ and $0.2 \%$ APF solutions. The fracture mode changed from ductile to brittle when the applied stress was lower than $500 \mathrm{MPa}$ in $2.0 \%$ APF solution. On the other hand, the delayed fracture 
did not occur within $1000 \mathrm{~h}$ in neutral $\mathrm{NaF}$ solutions, although general corrosion was also observed similar to that in APF solutions. The amount of absorbed hydrogen was 5000-6500 mass ppm under an applied stress in $2.0 \%$ APF solution for $24 \mathrm{~h}$. It was concluded that the immersion in fluoride solutions could result in degradation of the mechanical properties and fracture of beta titanium alloy associated with hydrogen absorption. In next research [7] the hydrogen absorption behavior of a beta titanium alloy in acid fluoride solutions was analysed by hydrogen thermal desorption. The amount of absorbed hydrogen increased with immersion time in a $2.0 \%$ APF solution. In the case of an immersion time of $60 \mathrm{~h}$, the amount of absorbed hydrogen exceeded 10,000 mass ppm. The amount of hydrogen absorbed in the $0.2 \%$ APF solution was several times smaller and hydrogen absorption saturated after $48 \mathrm{~h}$. During the later stage of immersion, the amount of absorbed hydrogen markedly increased under higher applied stress. Thus, both papers clearly show that in acidic solutions, hydrogen may be absorbed in quantities sufficient to enhance hydride-related degradation and that hydrogen content increases in tensile conditions. Generally, the $2 \%$ content of fluorides in acidic solution and about $500 \mathrm{MPa}$ seems necessary to promote degradation.

It is noteworthy that $[8,9]$ hydrogen embrittlement can appear in APF solutions also in lower $\mathrm{Ti}$ content, the Ni-Ti alloys. Upon immersion in a $2.0 \%$ APF solution with a $\mathrm{pH}$ of 5.0, tensile strength decreased markedly with immersion time, and the fracture mode changed from ductile to brittle due to brittle layer formation at the peripheral part of the cross section of the specimen. The amount of absorbed hydrogen increased linearly with immersion time, and it reached above 5,000 mass ppm after $24 \mathrm{~h}$. As the amount of absorbed hydrogen was larger than 500 mass ppm, the degradation of mechanical properties was recognized. The tensile properties and fracture mode, on the other hand, scarcely changed in a $0.2 \% \mathrm{APF}$ solution. Thus, the fluoride content can be a substantial factor.

Titanium is generally highly resistant to corrosion. Its corrosion resistance drastically decreases at low $\mathrm{pH}$ : as observed, the Ti6Al4V alloy is degraded after 3 weeks in lactic and formic acid [10]. Titanium can also be degradded in presence of fluoride ions. In [11] the problem of presence of fluorides in toothpastes and prophylactic gels on corrosion of titanium implants was examined. As shown, fluorides may cause crevice and pitting process when $\mathrm{pH}$ drops below 3.5, and above this value no serious degradation was observed. Another research [12] focused on corrosion resistance of titanium in $1 \% \mathrm{NaCl}$ containing $0.1 \% \mathrm{NaF}$, at $\mathrm{pH}=6$, under different elastic tensile strains, from 0 to $4 \%$. The NaF concentration and elastic tensile strain influenced the polarization resistance which decreased with an increasing $\mathrm{NaF}$ concentration and elastic tensile strain. As concluded, at NaF concentration lower than $0.01 \%$, formation of a protective $\mathrm{TiO}_{2}$ layer protects the metal, and at $0.1 \% \mathrm{NaF}$ content, the protectiveness of $\mathrm{TiO}_{2}$ is destroyed by fluoride ions, leading to severe corrosion of titanium.

So far research has brought out the results which suggest that corrosion, stress-enhanced corrosion and hydrogen-enhanced degradation may appear in Ti alloys and even work jointly. However, there has been no attempt to assess the risk of environment-enhanced damage by Slow Stress Rate Test, the best for prediction of such degradation, for the Ti13Nb13Zr alloy, a good candidate for modern titanium implants, in conditions closer to real ones. This research has been then aimed to characterise these phenomena, important for long term titanium implants, when in contact with fluoride ions. 


\section{MATERIALS AND METHODS}

The two-phase $(\alpha+\beta) \operatorname{Ti13Zr13Nb}$ alloy was inwestigated. The standard specimens for tensile test were prepared from the alloy sheet of $80 \times 220 \times 2 \mathrm{~mm}$, two for each test. The specimens are shown in Fig. 1.

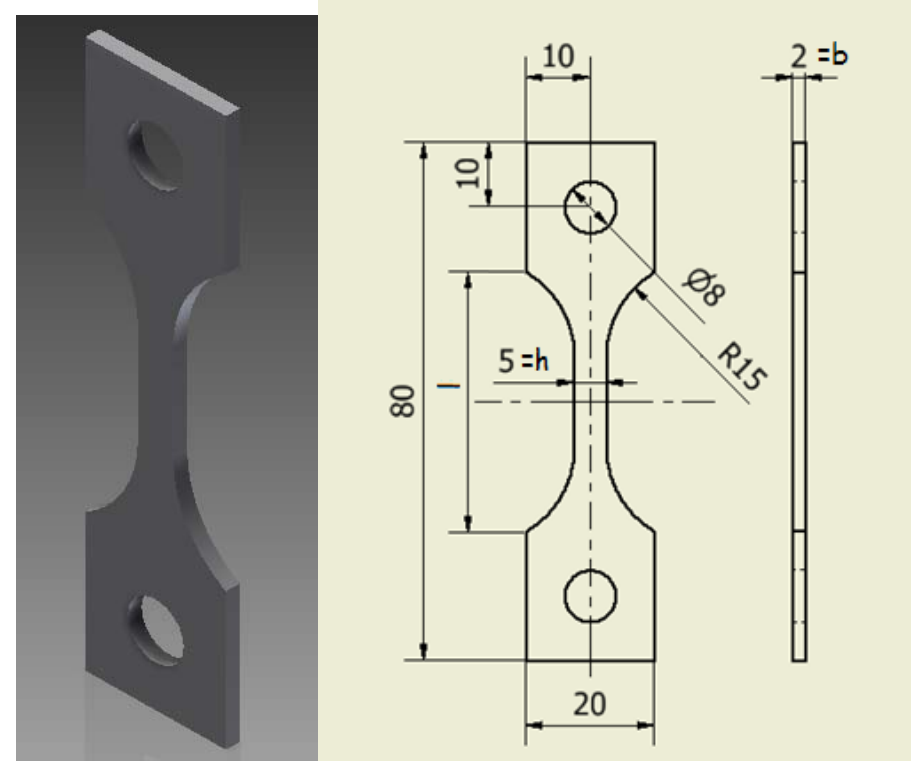

Fig. 1. Specimen for tensile test

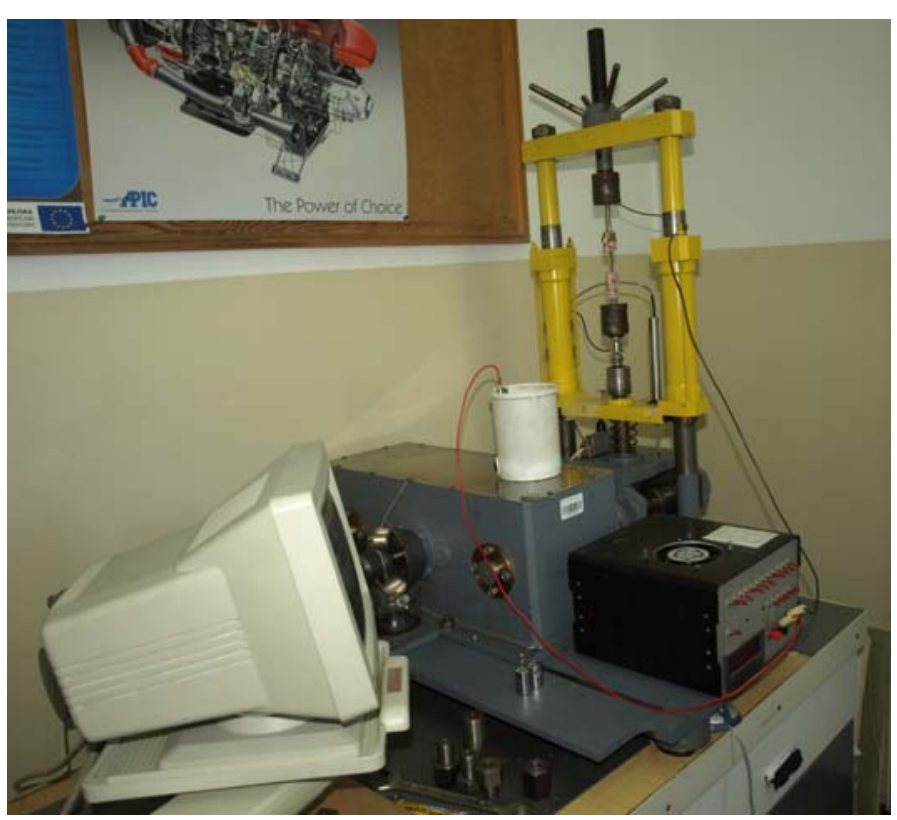

Fig. 2. Equipment for slow strain rate tests 
The slow strain rate tests were made at $10^{-5} \mathrm{~s}^{-1}$ tension rate. The equipment used for tests is demonstrated in Fig. 2. The clamps made of duplex stainless steel are shown in Fig. 3. The specimen was fully immersed in a plastic container (Fig. 4). The cathodic polarisation was applied by means of direct voltage supply and polarising Pt electrode (Fig. 5).

The tests were made either in laborarory air or in artificial saliva solution, with or without 0.1 mass pct. of HF, at open circuit potential or at cathodic polarisation of current density 100 $\mathrm{A} / \mathrm{m}^{2}$. The artificial saliva composed of (in $\mathrm{g} / \mathrm{dm}^{3}$ ): $\mathrm{NaCl} 1.2, \mathrm{KCl} 1.2, \mathrm{Na}_{2} \mathrm{~S} 6.015, \mathrm{Na}_{2} \mathrm{HPO} 4$ 4.14, $\mathrm{CaCl} 2$ 2.04, urea $\mathrm{CO}\left(\mathrm{NH}_{2}\right)_{2}$ 3.0, lactic acid 29.1.

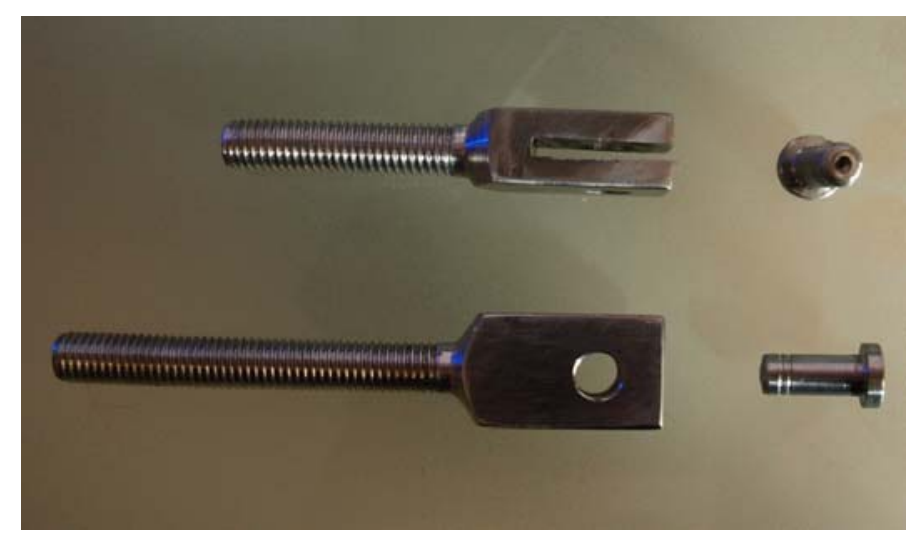

Fig. 3. Clamps fixing the specimens

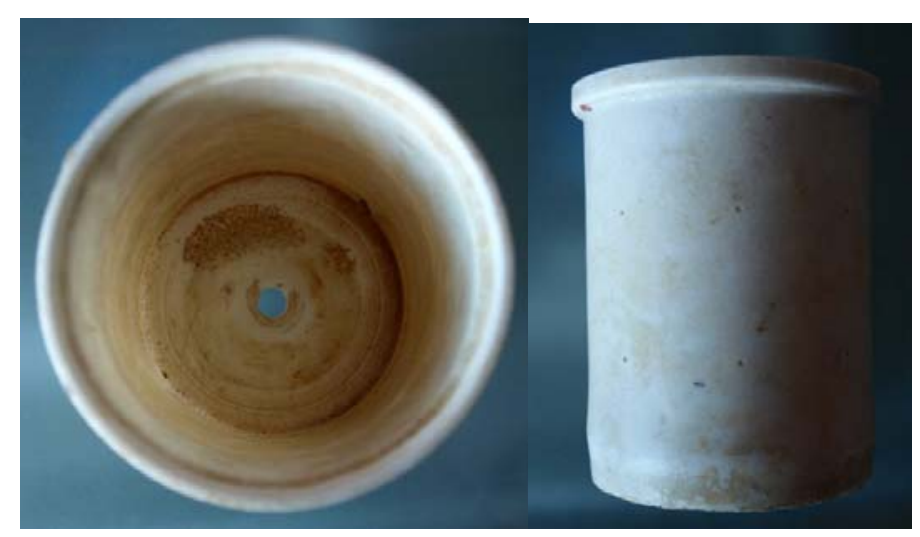

Fig. 4. Electrolytic cell for slow strain rate test

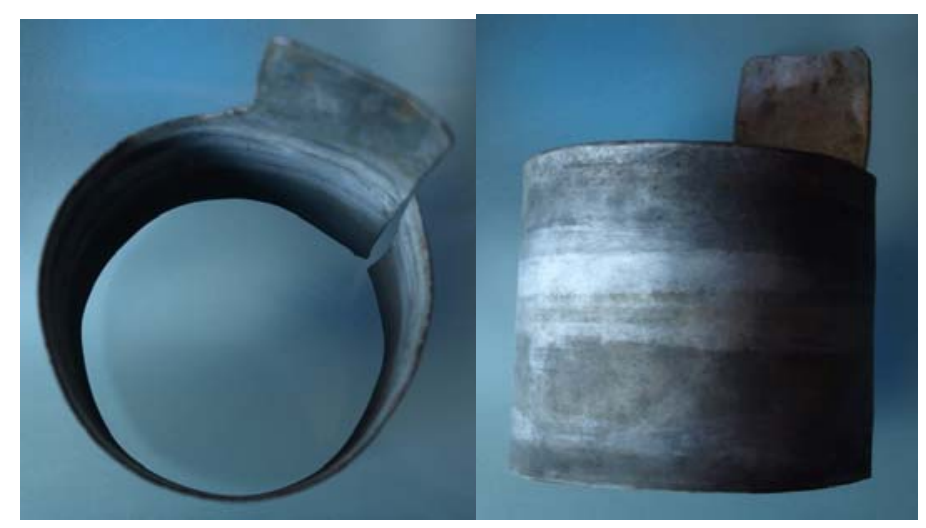

Fig. 5. Polarising electrode 


\section{RESULTS AND DISCUSSION}

Table 1 illustrates results of slow strain rate tests in different conditions. Taking into account the error made at calculation of proof stress, the results may be summarised as follows: (i) no effect of an exposure in artificial saliva, (ii) moderate effect of cathodic polarisation and (iii) signficant effect of presence of fluorides are observed.

Table 1. Results of slow strain rate tests in different conditions

\begin{tabular}{|l|c|c|c|c|c|}
\hline Environment & $\begin{array}{c}\text { Cathodic } \\
\text { current density } \\
\mathrm{A} / \mathrm{m}^{2}\end{array}$ & $\begin{array}{c}\text { Tensile } \\
\text { strength } \\
\mathrm{MPa}\end{array}$ & Yield stress & Elongation & $\begin{array}{c}\text { Time-to- } \\
\text { failure }\end{array}$ \\
\hline Laboratory air & 0 & 858 & 743 & $\mathrm{MPa}$ & $\mathrm{h}$ \\
\hline Artificial saliva & 0 & 866 & 684 & 4.3 & 22.05 \\
\hline Artificial saliva & 100 & 828 & 690 & 4.4 & 22.00 \\
\hline $\begin{array}{l}\text { Artificial saliva } \\
\text { + fluorides }\end{array}$ & 0 & 764 & 653 & 3.3 & 17.20 \\
\hline
\end{tabular}

Figs. 6-13 demonstrate the examinations of fracture faces after slow strain rate tests. For specimen tensed in air the ductile fracture is observed. No brittle cracks appear.

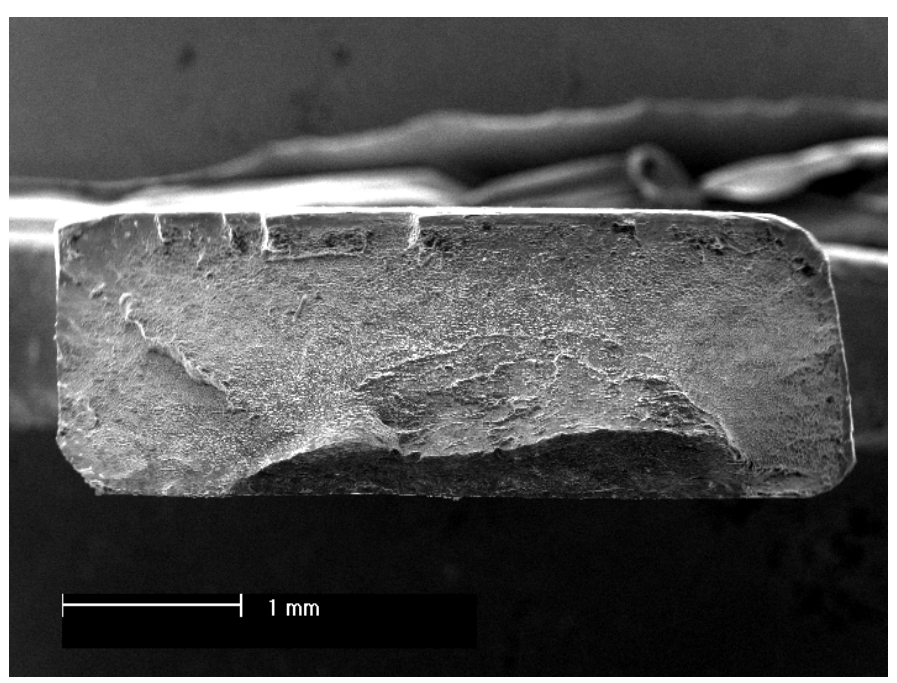

Fig. 6. Fracture surface of a specimen tensed in air 


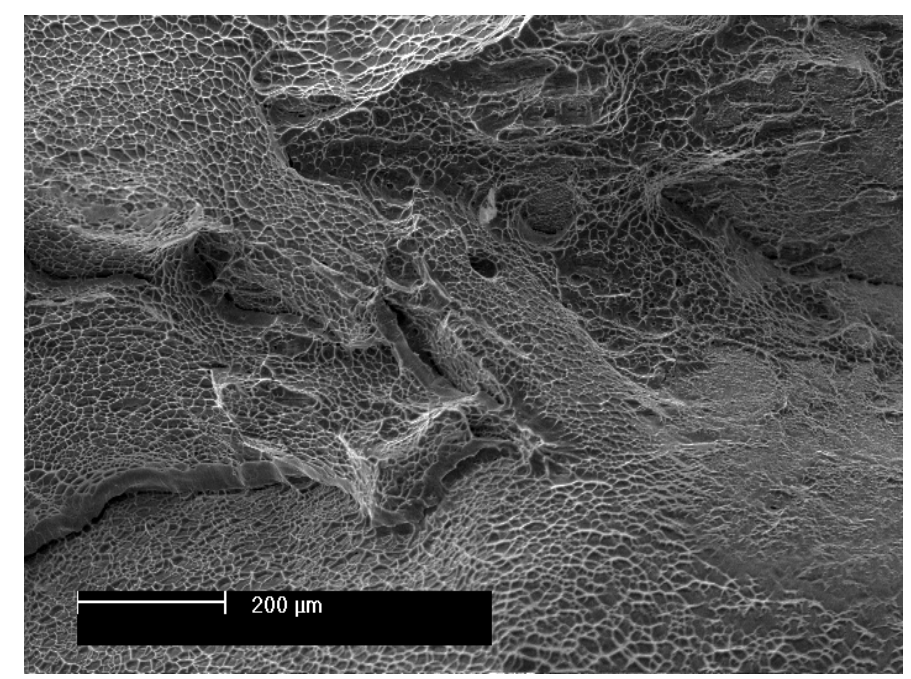

Fig. 7. Fracture surface of a specimen tensed in air

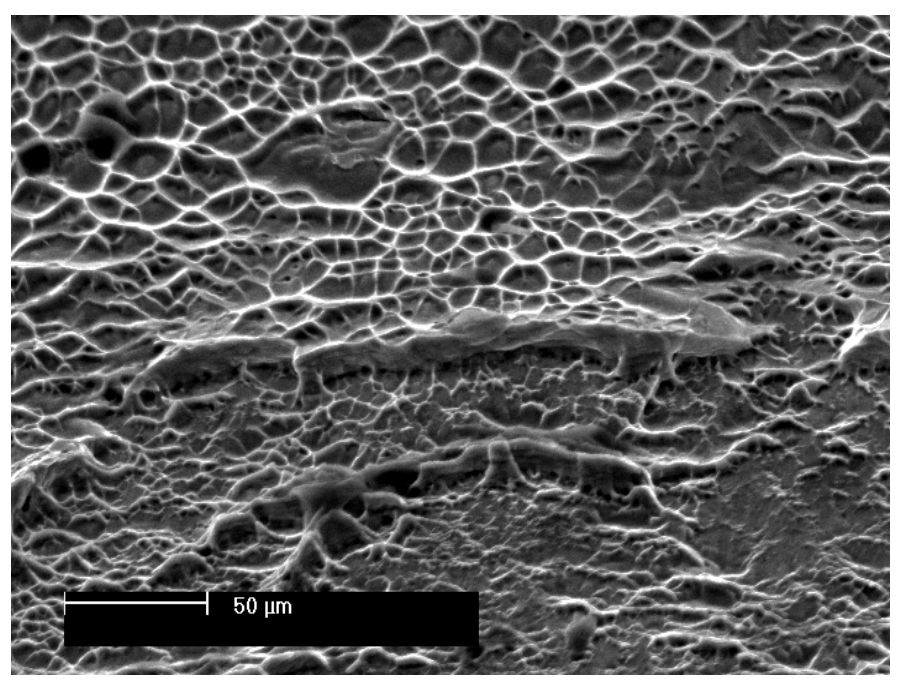

Fig. 7 . Fracture surface of a specimen tensed in air

Similar ductile appearance is shown for specimen fractured in artificial saliva (Figs. 8-10).

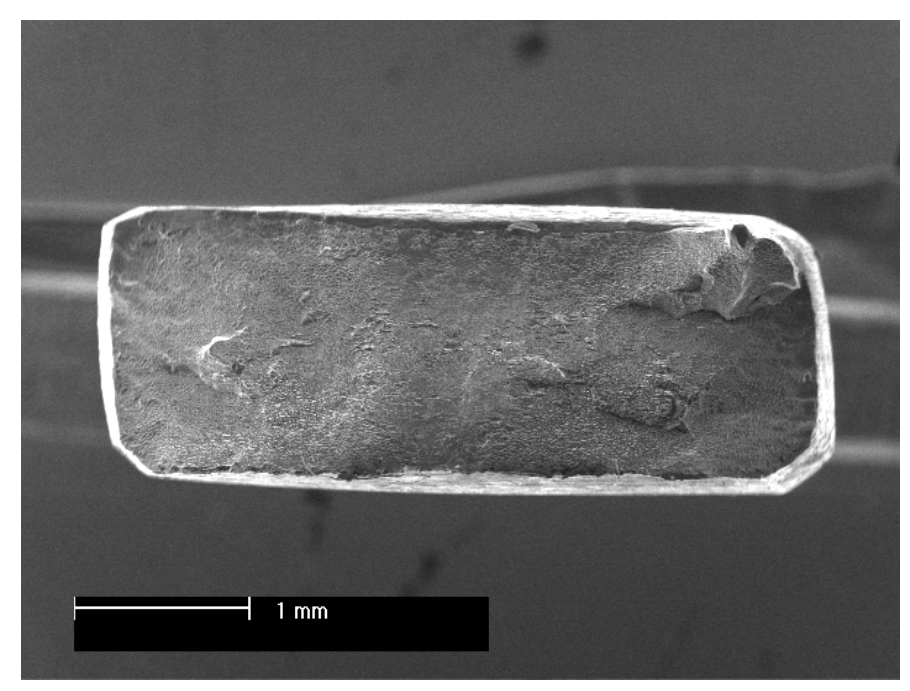

Fig. 8. Fracture surface of a specimen tensed in artificial saliva 


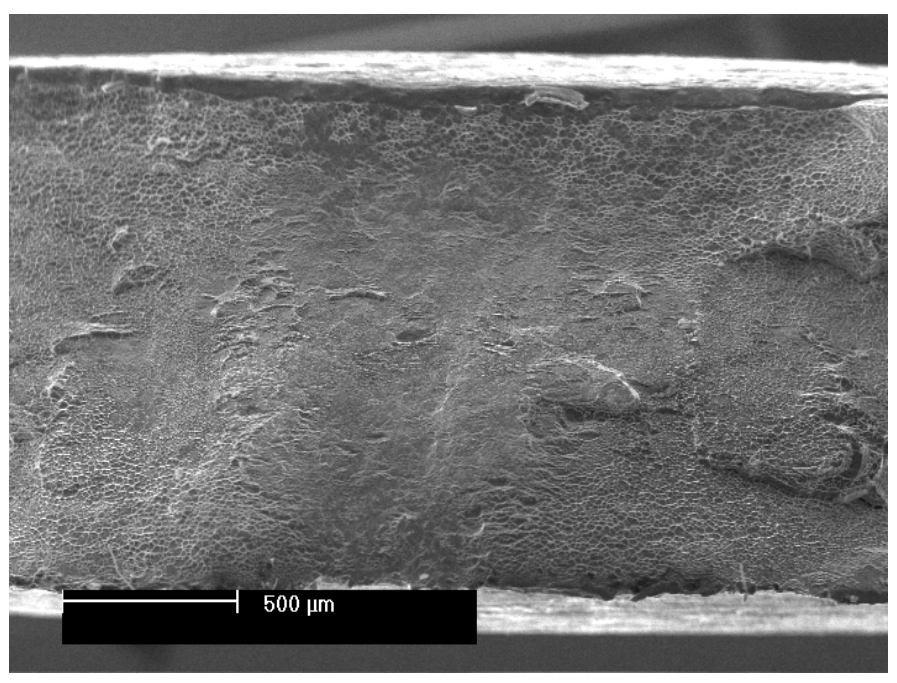

Fig. 9. Fracture surface of a specimen tensed in artificial saliva

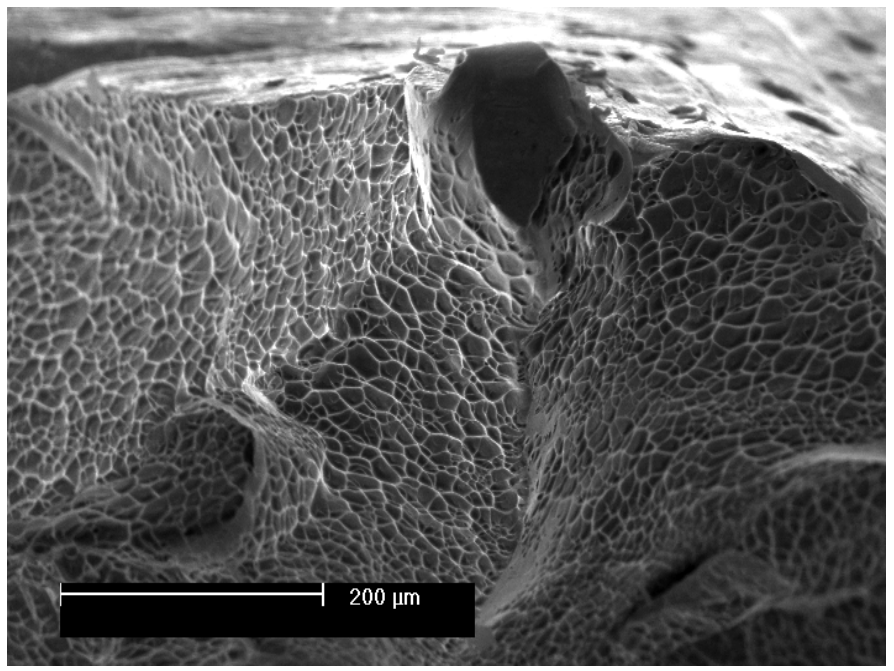

Fig. 10. Fracture surface of a specimen tensed in artificial saliva

On the contrary, for specimen fractured in artificial saliva at cathodic polarisation the birttler appearance is typical. The single transcrystalline cracks and decohesion is observed (Figs. 1113). 


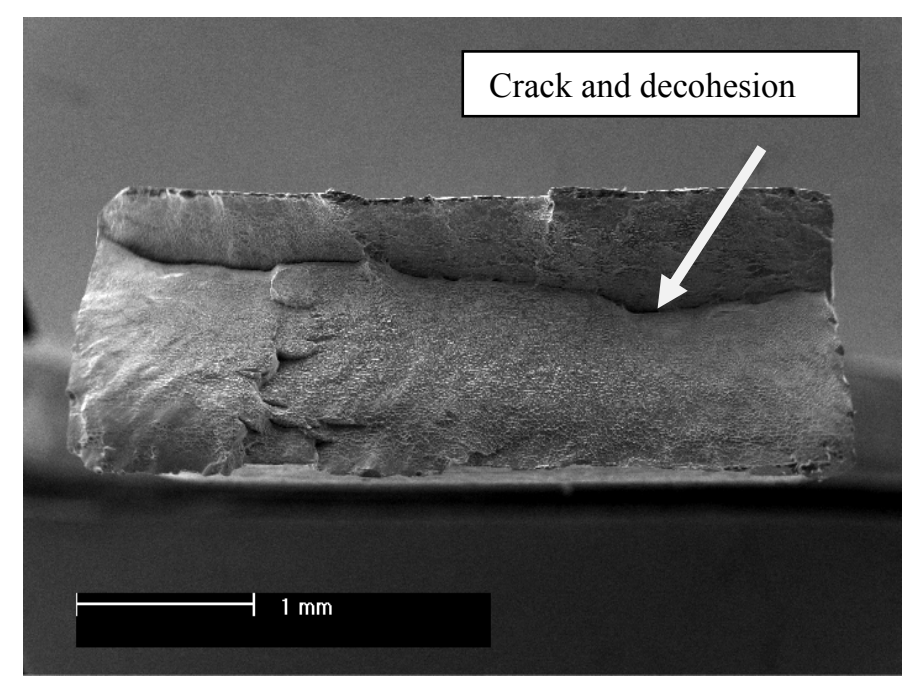

Fig. 11. Fracture surface of a specimen tensed in artificial saliva, at cathodic polarisation, $100 \mathrm{~A} / \mathrm{m}^{2}$ current density

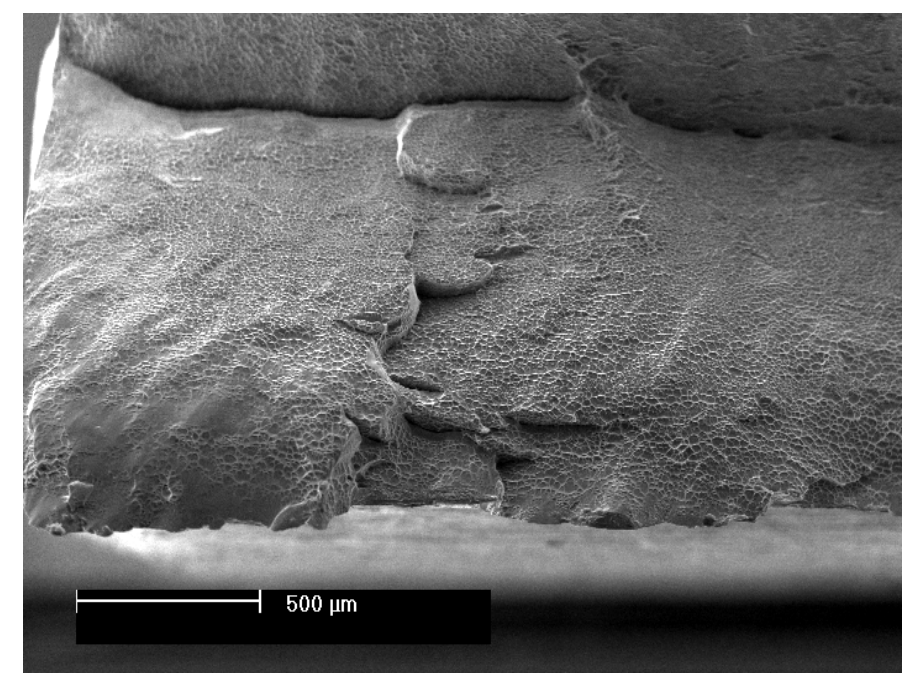

Fig. 12. Fracture surface of a specimen tensed in artificial saliva, at cathodic polarisation, $100 \mathrm{~A} / \mathrm{m}^{2} \mathrm{current}$ density

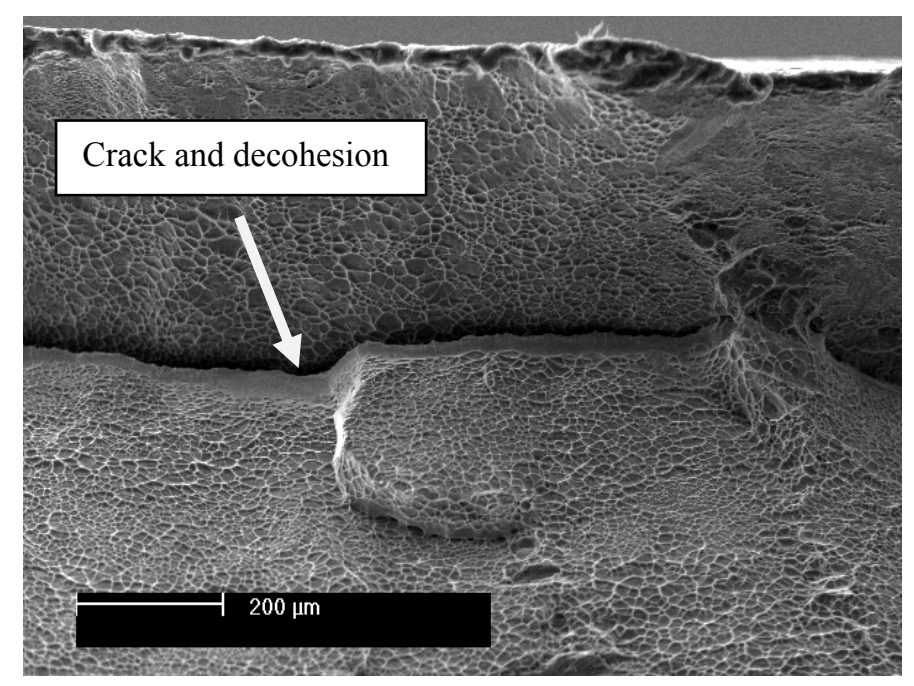

Fig. 13. Fracture surface of a specimen tensed in artificial saliva, at cathodic polarisation, $100 \mathrm{~A} / \mathrm{m}^{2}$ current density 
In Figs. 14-17 the brittle fracture with decohesion is shown for specimen tensed in artificial saliva with an addition of fluorides.

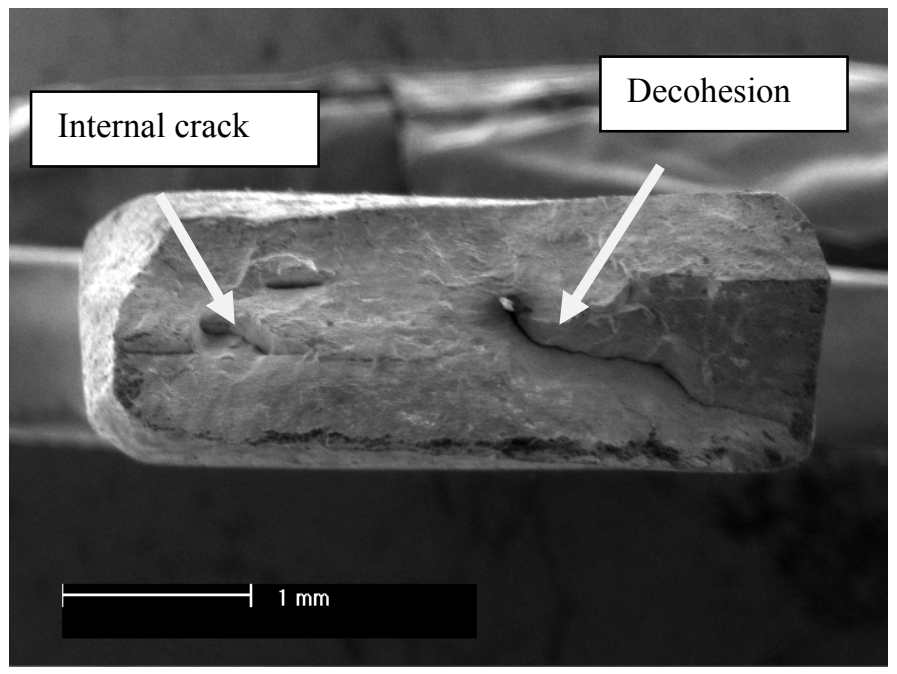

Fig. 14. Fracture surface of a specimen tensed in artificial saliva in presence of fluorides

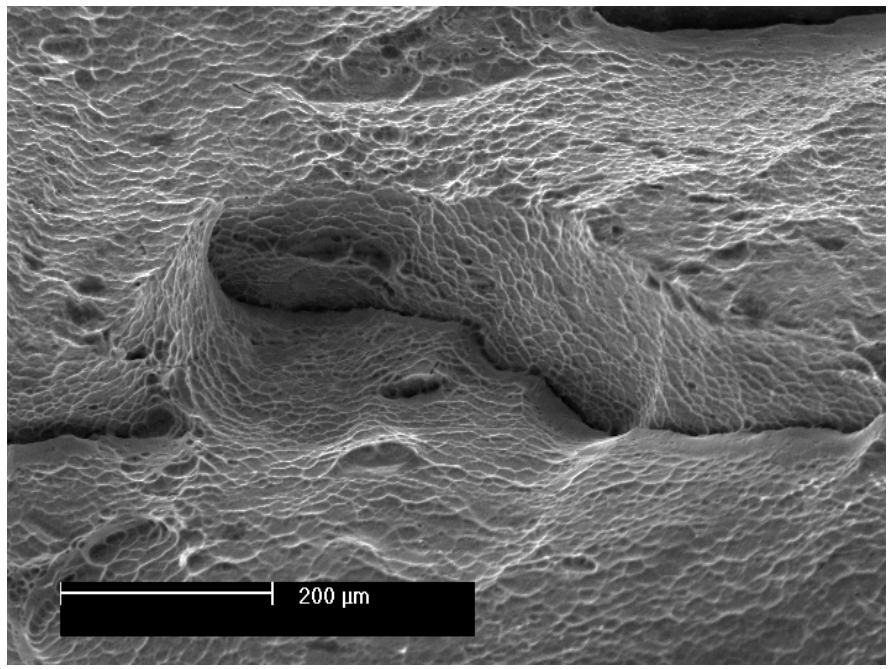

Fig. 15. Fracture surface of a specimen tensed in artificial saliva in presence of fluorides

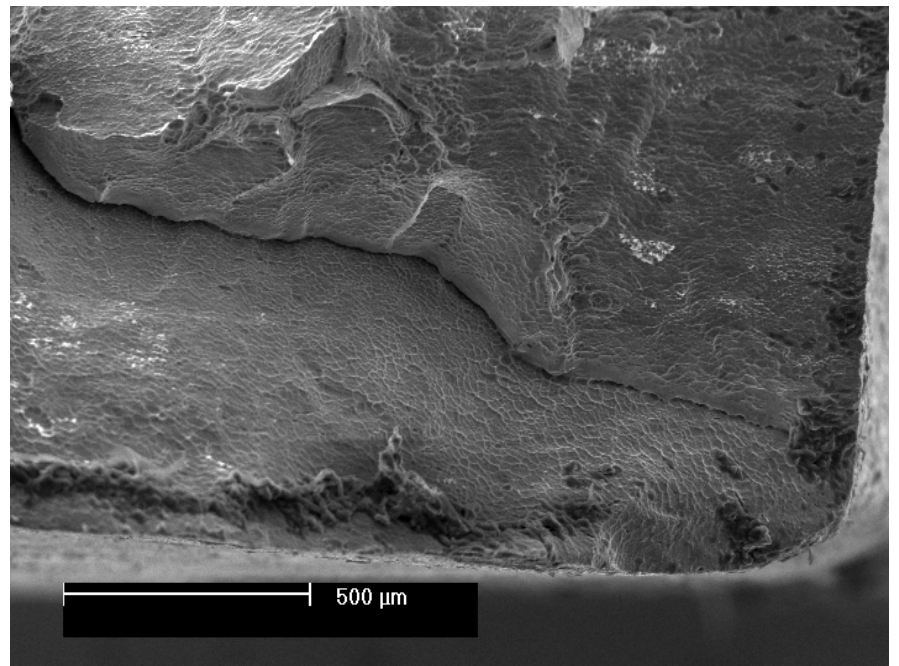

Fig. 16. Fracture surface of a specimen tensed in artificial saliva in presence of fluorides 


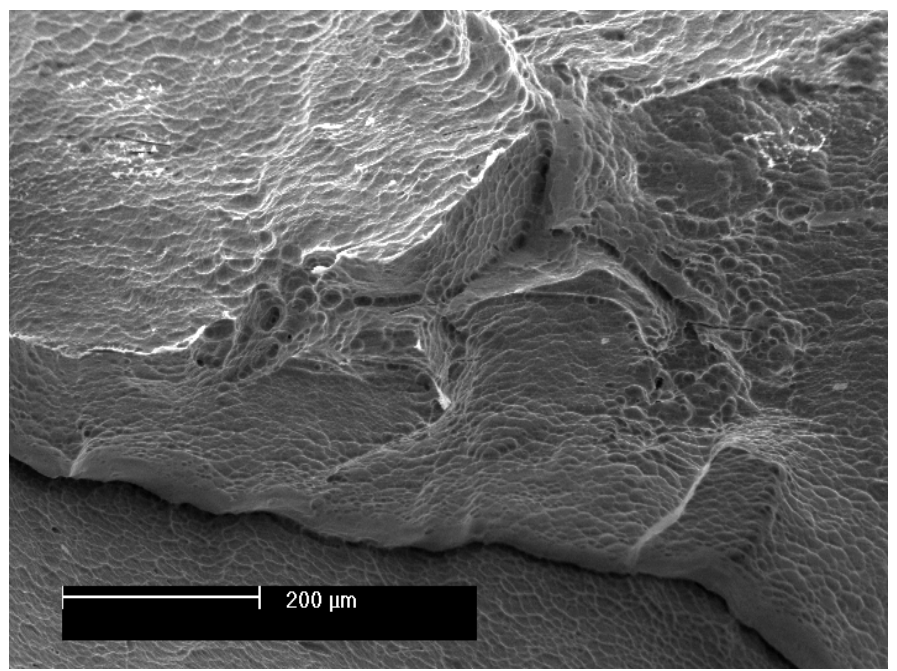

Fig. 17. Fracture surface of a specimen tensed in artificial saliva in presence of fluorides

The obtained results, their appearance and intensity, can be explained in terms of environment-related brittle cracking. The artificial saliva itself is no liquid which could enhance the initiation and propagation of brittle cracks, and ductile appearance, typical of this alloy tensed in air, can be observed. That means that even if at mild acidic conditions some amount of hydrogen is evolved, likely an oxide layer remains the effective barrier against its entry into metal.

The application of cathodic polarisation increases permeation of hydrogen through the oxide layer and in such a manner the hydrogen amount in the metal. The appearance of brittle cracking is an evidence that the hydrogen content in the metal is above the limit solubility of hydride formation and the brittle cracking is caused by hydride formaton and decom position, presumably the $\gamma$ hydride.

The mostly interesting is an appearance of brittle cracking in artificial saliva with fluoride ions. Two explanations may be given at the moment. At first, the fluoride ions cause damage of the oxide layer which constitutes no more high barrier against hydrogen entry. Another model may involve stress-enhanced corrosion and degradation similar to the iodine-enhanced SCC of Zr alloys [13]. To distinguish both possibilities, characterise chemical and mchanical determinants and modelise the degradation, more research is necessary and will be performed as extremely important for long term stability of dental implants.

Only specimens significantly prone to degradation of mechanical properties and microstructure are those exposed to fluorides and not subject to cathodic hydrogen. It may mean that localised corrosion is very important for initiation of cracking.

\section{CONCLUSIONS}

The Ti13Zr13Nb alloy may undergo brittle cracking in artificial saliva either under cathodic polarisation or in presence of fluoride ions.

The brittle cracking may be atttributed either to hydrides` formation and decomposition or stress corrosion cracking enhanced by fluorides. 


\section{REFERENCES}

1. Brunette D.M., Tengvall P., Textor M., Thomsen P.: Titanium in medicine. Springer, Germany 2001.

2. Liu X., Chu P.K., Ding Ch.: Surface modification of titanium, titanium alloys, and related materials for biomedical applications. Mater. Sci. Eng. 47 (2004), 49-121.

3. Kaszuwara W.: Shape memory alloys. Inżynieria Materiałowa 2 (2004), 61-64. In Polish; English abstract.

4. Zieliński A., Sobieszczyk S., Seramak T., Serbiński W., Świeczko-Żurek B., Ossowska A.: Biocompatibility and bioactivity of load-bearing metallic implants. Advances in Materials Science 10, No. 4 (2010), 21-31.

5. Zieliński A.: Niszczenie wodorowe metali nieżelaznych i ich stopów. Gdańskie Towarzystwo Naukowe, Gdańsk 1999. In Polish; English summary.

6. Kaneko K., Yokoyama K., Moriyama K., Asaoka K., Sakai J., Nagumo M.: Delayed fracture of beta titanium orthodontic wire in fluoride aqueous solutions. Biomaterials 24 (2003), 2113-2120.

7. Ogawa T., Yokoyama K., Asaoka K., Sakai J.: Hydrogen absorption behavior of beta titanium alloy in acid fluoride solutions. Biomaterials 25 (2004) 2419-2425.

8. Yokoyama K., Hamada K., Moriyama K., Asaoka K.: Degradation and fracture of Ni-Ti superelastic wire in an oral cavity. Biomaterials 22 (2001), 2257-2262.

9. Yokoyama K., Kaneko K., Ogawa T., Moriyama K., Asaoka K., Sakai J.: Hydrogen embrittlement of work-hardened Ni-Ti alloy in fluoride solutions. Biomaterials 2004 in press.

10. Koike M., Fuji H.: The corrosion resistance of pure titanium in organic acids. Biomater. 22 (2001), 2931-2936.

11. Reclaru L., Meyer J.-M.: Effect of fluorides on titanium and other dental alloys in dentistry. Biomaterials 19 (1998), 85-92.

12. Huang H.-H.: Effects of fluoride concentration and elastic tensile strain on the corrosion resistance of commercially pure titanium. Biomaterials 23 (2002), 59-63.

13. Françon V., Fregonese M., Abe H., Watanabe Y : Iodine-induced stress corrosion cracking of Zircaloy-4: identification of critical parameters involved in intergranular to transgranular crack propagation. 